\title{
Influência da qualidade microbiológica da água de dessedentação na morfologia intestinal de frangos de corte ${ }^{1}$
}

\author{
Lizandra Amoroso ${ }^{2 *}$, Silvana M. Baraldi-Artoni ${ }^{2}$, Nilce M. Soares ${ }^{3}$, Fernanda R. Pinto ${ }^{4}$, \\ Maria R. Pacheco ${ }^{2}$, Alex L. Sagula ${ }^{5}$, Juan Carlos Ríos Alva ${ }^{2}$ e Patricia Amoroso ${ }^{6}$
}

\begin{abstract}
Amoroso L., Baraldi-Artoni S.M., Soares N.M., Pinto F.R., Pacheco M.R., Sagula A.L., Alva J.C.R. \& Amoroso P. 2015. [Influence of microbiological quality of drinking water in the intestinal morphology of broilers.] Influência da qualidade microbiológica da água de dessedentação na morfologia intestinal de frangos de corte. Pesquisa Veterinária Brasileira 35(1):80-88. Departamento de Morfologia e Fisiologia Animal, Faculdade de Ciências Agrárias e Veterinárias, Universidade Estadual Paulista, Campus de Jaboticabal, Rodovia de Acesso Paulo Donato Castellane s/n, Km 5, Jaboticabal, SP 14884-900, Brazil. E-mail: lizandra@fcav.unesp.br

To evaluate if microbiological quality of drinking water has an effect on intestinal morphology of broilers, the weekly water consumption by them was verified, and microbiological analysis of water samples, scanning electron microscopy and small intestine histology of broilers treated with filtered and not filtered water was conducted. Chickens that ingested filtered water had access to fewer fecal microorganisms (2.52 \pm 0.99 Most Probable Number MPN of fecal coliforms and 1.17 \pm 1.25 MPN of Escherichia coli) compared to those who drank no filtered water ( $3.62 \pm 0.67$ and $2.53 \pm 1.13 \mathrm{MPN})$. At 14, 21 and 45 days old, the duodenum, jejunum and ileum of 96 birds were sampled. After laboratory routine, samples preserved in glutaraldehyde were eletronmicrographed and evaluated by villous density, and the material maintained in Bouin's solution was destinated to histological slides that were analyzed morphometrically. The duodenum of birds that ingested not filtered water had the highest density of villi in response to microbiological water quality. In intestinal morphometry, were observed that birds receiving not filtered water showed increase in intestinal crypts depth and presented larger villi compared with birds that ingested filtered water. It is cocluded that filtered water, offered to broilers in a life span of 45 days, favors the maintenance of intestinal integrity.
\end{abstract}

INDEX TERMS: Water quality, filtered water, birds, broilers, intestinal integrity, scanning electron microscopy.

RESUMO.- Para avaliar se a qualidade microbiológica da água de dessedentação intervém na morfologia intestinal de frangos de corte, foram analisados o consumo semanal de água, a microbiologia de amostras de água, a microscopia eletrônica de varredura e a histologia do intestino delgado de frangos de corte tratados com água filtrada e

\footnotetext{
${ }^{1}$ Recebido em 4 de abril de 2014.

Aceito para publicação em 30 de janeiro de 2015.

${ }^{2}$ Departamento de Morfologia e Fisiologia Rural, Faculdade de Ciências Agrárias e Veterinárias de Jaboticabal (FCAVJ), Universidade Estadual Paulista (Unesp), Rodovia de Acesso Paulo Donato Castellane s/n, Km 5, Jaboticabal, SP 14884-900, Brasil. *Autor para correspondência: lizandra@fcav.unesp.br

${ }^{3}$ Unidade de Pesquisa e Desenvolvimento do Instituto Biológico, Av. Gaspar Ricardo 1700, Bastos, SP 17690-000, Brasil.
}

não filtrada. Os frangos que ingeriram água filtrada tiveram acesso ao menor número de micro-organismos fecais $(2,52 \pm 0,99$ Número Mais Provável (NMP) de coliformes fecais e 1,17 $\pm 1,25$ NMP de Escherichia coli) em relação aos que ingeriram água não filtrada $(3,62 \pm 0,67 \mathrm{NMP}$ e $2,53 \pm 1,13$ NMP). Aos 14, 21 e 45 dias de vida, foram co-

\footnotetext{
${ }^{4}$ Departamento de Veterinária Preventiva, Faculdade de Veterinária, Universidade Federal de Pelotas (UFPel), Campus Universitário Capão do Leão s/n, Prédio 1, Pelotas, RS 96010-900, Brasil.

${ }^{5}$ Departamento de Engenharia Rural, Faculdade de Ciências Agrárias e Veterinárias de Jaboticabal (FCAVJ), Universidade Estadual Paulista (Unesp), Rodovia de Acesso Paulo Donato Castellane s/n, Km 5, Jaboticabal, SP 14884-900, Brasil.

${ }^{6}$ Centro Universitário da Fundação Educacional de Barretos (UNIFEB), Av. Professor Roberto Frade Monte 389, Barretos, SP 14783-226, Brasil.
} 
lhidas amostras do duodeno, jejuno e íleo de 96 aves. Após rotina laboratorial, as amostras conservadas em glutaraldeído foram eletronmicrografadas e analisadas quanto à densidade de vilos e o material mantido em solução de Bouin foi destinado à confecção de lâminas histológicas que foram analisadas morfometricamente. 0 duodeno das aves que receberam água não filtrada apresentou maior densidade dos vilos em resposta à qualidade microbiológica da água. Na morfometria intestinal, observou-se que aves que receberam água não filtrada apresentaram aumento na profundidade das criptas intestinais e elevada altura das vilosidades em relação às aves que ingeriram água filtrada. Infere-se que a água filtrada, oferecida aos frangos de corte em um período de vida de 45 dias, favorece a manutenção da integridade intestinal.

TERMOS DE INDEXAÇÃO: Qualidade da água, água filtrada, aves, frangos de corte, integridade intestinal, microscopia eletrônica de varredura.

\section{INTRODUÇÃO}

Os coliformes fecais e os termotolerantes, como Escherichia coli, são reconhecidos mundialmente como indicadores de contaminação fecal na água potável (Gruber et al. 2014). A presença de agentes patogênicos nas fezes, como enterococos e micro-organismos mesófilos, na água, é fator de risco à saúde dos animais (Pinto et al. 2010). Micro-organismos enteropatogênicos geralmente apresentam baixas concentrações em ambientes aquáticos quando comparados à diversificada microbiota existente. Pelo fato destes micro-organismos usualmente aparecerem de forma intermitente, e, em reduzido número na água, são pesquisados outros grupos que estão presentes com os patogênicos. Shibata et al. (2004), afirmaram que os micro-organismos indicadores são aqueles encontrados em elevadas concentrações nas fezes. Como integrante do grupo de coliformes fecais, a espécie Escherichia coli é um indicador específico e confiável de contaminação fecal em água potável (Odonkor \& Ampofo 2013). Na atualidade, é permitido até 200 NMP/100 $\mathrm{mL}$ de E. coli na água de consumo animal (Brasil 2008).

Como nutriente essencial no metabolismo, a água ingerida pelas aves é utilizada na hidrólise digestiva, no transporte de nutriente e no equilíbrio da pressão osmótica intracelular. Ao sofrer contaminação bacteriológica, a água de baixa qualidade torna-se menos disponível ao consumo, interfere negativamente na digestão de nutrientes, além de proporcionar vazamentos de nipples, acarretando em umedecimento de cama (Fairchild \& Ritz 2009). Como todas as aves têm acesso à mesma fonte de dessedentação, o uso de água de qualidade duvidosa favorece a disseminação de enfermidades, ao carrear agentes patogênicos de doenças de interesse em Saúde Pública. Além disso, a instalação de bactérias fecais no bebedouro contamina o sistema de fornecimento de água e propicia microambiente favorável ao desenvolvimento de micro-organismos, o que caracteriza a formação de biofilmes (Gama et al. 2008).

0 epitélio intestinal forma uma barreira coesa que impede a entrada, a disseminação e a instalação de micro-organismos patogênicos em tecidos mais profundos (Ashida et al. 2012). A resposta às agressões ao epitélio ocorre por meio de modificações morfológicas no comprimento, número das vilosidades intestinais e profundidade de criptas intestinais (Aptekmann et al. 2001). As avaliações, quantitativa e qualitativa, da integridade intestinal permitem analisar a capacidade digestiva e absortiva do intestino e os danos à mucosa intestinal (Gomide Junior et al. 2004). Para que a água e alimentos previamente digeridos sejam absorvidos, o intestino delgado aumenta quatro vezes em relação ao peso corporal durante a primeira semana de vida (Corless \& Sell 1999). 0 desenvolvimento do epitélio ocorre através da divisão de células indiferenciadas nas criptas intestinais (Quinn et al. 2010). Estas células são constantemente renovadas através das "stem cells" presentes nas criptas intestinais que migram para o ápice da vilosidade e, finalmente, se deslocam para o lúmen. Quando há densa população de micro-organismos ocorrem mudanças na fisiologia intestinal, com aceleração ou atenuação do turnover celular prejudicando a digestão, o transporte e absorção de nutrientes (Leser \& Molbak, 2009). 0 uso de aditivos nutricionais na dieta promove maior densidade dos vilos em frangos de corte (Pelicano 2006, Sen et al. 2012). Como exemplo de fatores agressores à mucosa intestinal, aves inoculadas com Salmonella Enteritidis apresentam maiores quantidades de células caliciformes em relação às tratadas com ácidos orgânicos (Pickler et al. 2012). Já em aves desafiadas com Eimeria tenella, os probióticos favorecem a saúde intestinal e melhoram o desempenho (Giannenas et al. 2012). Considerando os relatos da literatura, observa-se que o estudo de patologias que afetam o intestino delgado e o uso de fatores tróficos adicionados à dieta são frequentemente relacionados com o comportamento morfológico da mucosa intestinal em frangos de corte. Entretanto, há carência de informações sobre a qualidade microbiológica da água e seus efeitos sobre a morfologia do intestino delgado.

O volume de água ingerido corresponde ao dobro do consumo de alimentos interferindo significativamente na constituição celular do organismo ao proporcionar movimento de substâncias através de membranas epiteliais (Collet 2012). Devido à relevância da água na homeostasia orgânica, o objetivo deste trabalho foi avaliar a influência da qualidade microbiológica da água filtrada e não filtrada sobre a morfologia de frangos de corte no período de um a 45 dias de idade.

\section{MATERIAL E MÉTODOS}

O experimento foi realizado nas dependências do Setor de Avicultura do Departamento de Zootecnia. Foram utilizados 1120 pintos de 1 dia, da linhagem Cobb, com distribuição inteiramente casualizada em 32 boxes, com 16 parcelas para cada tratamento e 35 aves por parcela. A metodologia de estudo foi analisada e aprovada pela Comissão de Ética e Bem Estar Animal no 000422-08 da Faculdade de Ciências Agrárias e Veterinárias de Jaboticabal.

Os tratamentos foram em número de dois: água filtrada e água não filtrada do Campus da Unesp de Jaboticabal, dispostos em boxes de forma intercalada. Para se obter água filtrada, foi utilizado equipamento da linha Hidrofiltros ${ }^{\circledR}$ (Fig.1), constituído de três elementos filtrantes. Na primeira etapa, a água passou por um filtro de 150 micrômetros $(\mu \mathrm{m})$ de polipropileno e poliéster, que foi empregado na pré-filtração para reter galhos, pedregu- 
lhos e grandes sedimentos. Na segunda etapa, o filtro de $25 \mu \mathrm{m}$, lavável, plissado de poliéster, reduzia a areia, o barro e o limo em suspensão na água. 0 terceiro filtro removeu o cloro, odor, sabor desagradável e a cor da água. A água não filtrada era obtida da torneira do galpão. Os dois tipos de água eram transportados em recipientes plásticos e transferidos por meio de um funil plástico para o galão de capacidade de 10 litros. As aves foram alojadas em galpão de alvenaria com piso de concreto, cama de maravalha com quatro centímetros de altura e cortina externa móvel. As instalações continham lâmpada infravermelha de 250 watts e comedouro infantil de um a sete dias de vida. No término da fase inicial, crescimento e final (8-45 dias de idade), os frangos receberam ração comercial em comedouro tubular, com acesso, à vontade, à água em bebedouro tipo nipple de três bicos por boxe durante todo o período experimental (Fig.2). A média do consumo semanal de água das 1120 aves foi determinada ao longo de todo o período experimental.

As condições microbiológicas da água de dessedentação foram avaliadas do período inicial de vida das aves até a saída do lote para abate, com colheitas realizadas em intervalos de sete dias em um total de sete colheitas. Foram pipetados $0,5 \mathrm{~mL}$ de tiossulfato de sódio em frascos de vidro com capacidade de $250 \mathrm{~mL}$ para a amostragem da água não filtrada, enquanto os frascos para a colheita da água do filtro não apresentavam tiossulfato de sódio, por não conter cloro. Os frascos estéreis foram utilizados para a colheita de $200 \mathrm{~mL}$ de amostra de cada tratamento, diretamente do bico do bebedouro nipple, por meio de espátula de madeira estéril (Fig.3). As amostras foram transportadas sob refrigeração para o

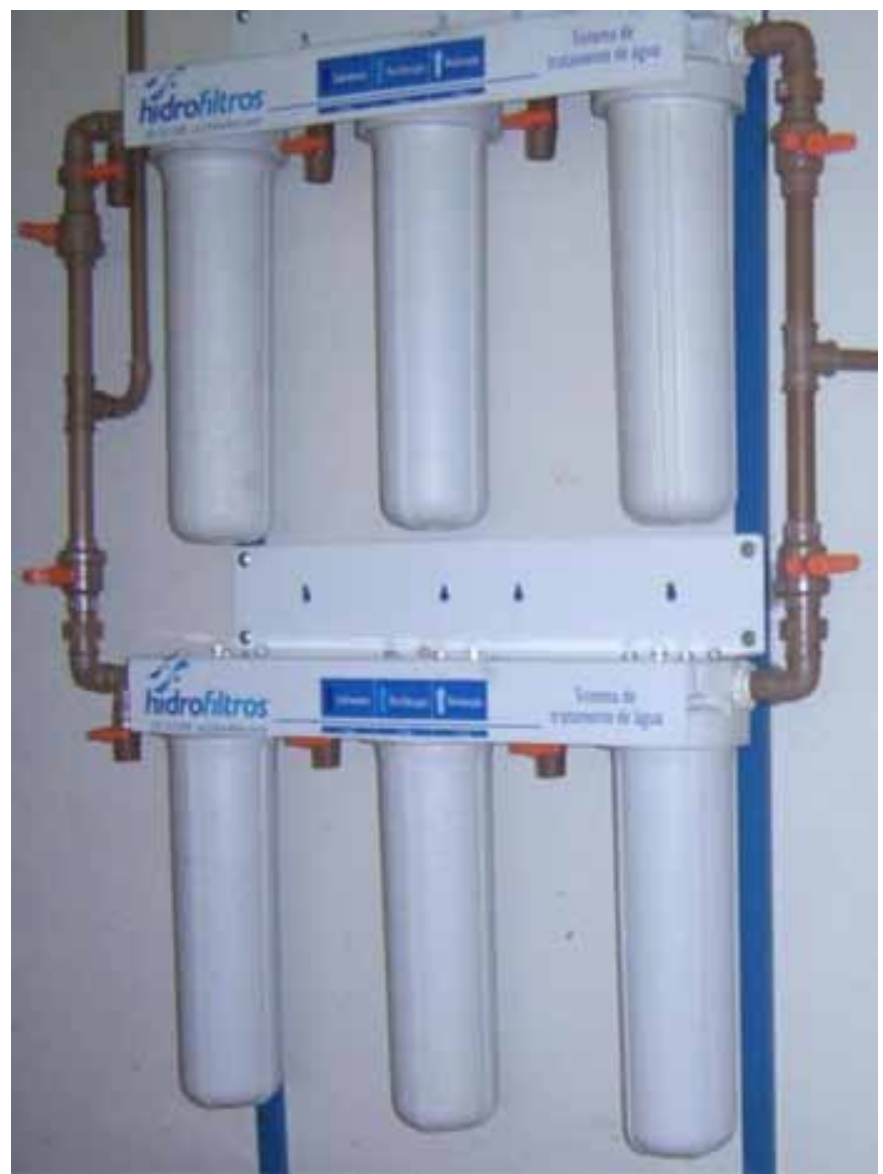

Fig.1. Filtro HF 5000 constituído por elementos filtrantes Big 5 HPC 10" big; Big 50 PF 10" big, Hidrofiltros ${ }^{\circledR}$, utilizado durante o experimento.

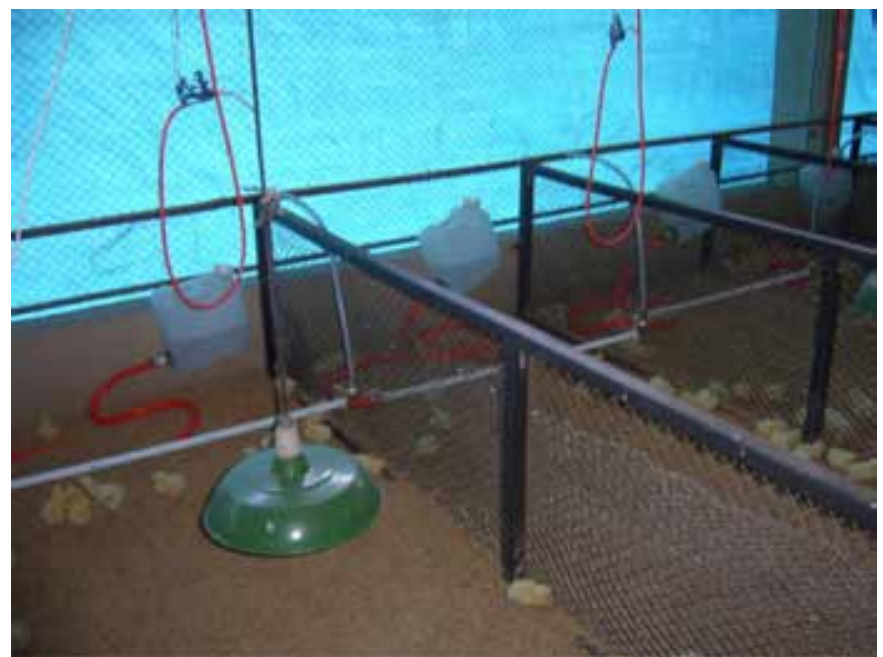

Fig.2. Galpão com nipple de três pontos de abertura de água para cada boxe, cama de maravalha e lâmpadas.

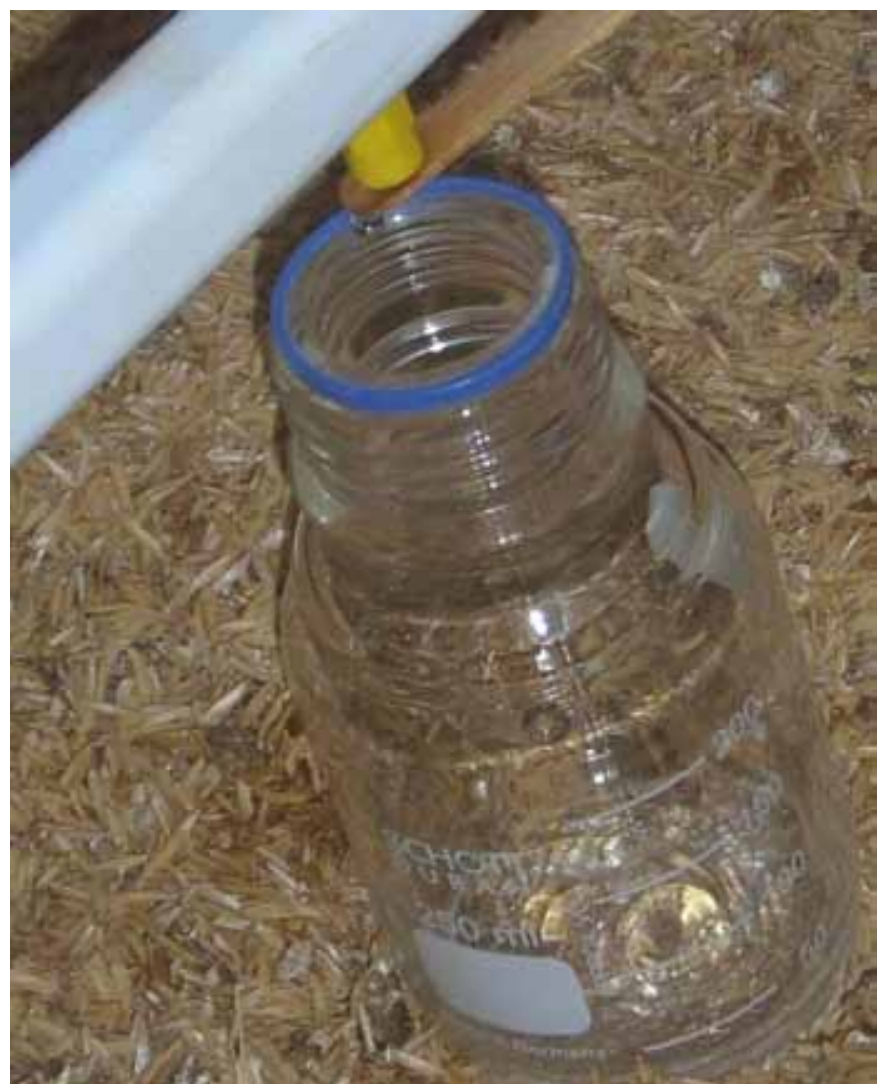

Fig.3. Colheita semanal de amostras de água no bico de bebedouros tipo nipple utilizando espátula de madeira estéril.

laboratório de Medicina Veterinária Preventiva, sendo realizadas análises bacteriológicas logo após a chegada das mesmas. Para a determinação de coliformes totais e Escherichia coli, utilizou-se o ensaio cromogênico empregando o Kit Colilert. Os resultados foram expressos em NMP/100 mL consultando a tabela de NMP fornecida pelo fabricante, em que são dados os limites de confiança de 95\% para cada valor de NMP determinado.

Decorridos 14, 21 e 45 dias de idade, 96 aves foram anestesiadas, sacrificadas e necropsiadas para a colheita do intestino delgado em duplicata, para a análise morfológica e morfométrica. 
Amostras da porção média do duodeno, jejuno e íleo de cada ave foram acondicionadas em frascos contendo solução conservadora de glutaraldeído $3 \%$ durante $48 \mathrm{~h}$ para utilização da técnica de microscopia eletrônica de varredura. Após este período, as mesmas foram lavadas por seis vezes consecutivas em tampão fosfato 0,1 M, pH 7,6 e então pós-fixadas em solução de tetróxido de ósmio a $1 \%$ durante 30 minutos, à temperatura de $4 \stackrel{\circ}{ } \mathrm{C}$. Posteriormente, $\mathrm{o}$ material foi novamente embebido com o mesmo tampão por seis vezes consecutivas, desidratado em concentrações crescentes de álcool etílico (30, 50, 70, 80, 90 e 100\%), 20 minutos em cada concentração, sendo que, na última, as amostras foram lavadas por três vezes consecutivas, 20 minutos em cada lavagem. Depois de cada desidratação, o material passou pela câmara de secagem do secador de ponto crítico, mediante a utilização de dióxido de carbono. 0 material foi então montado em porta objeto apropriado, recoberto com uma camada de $30 \mathrm{~nm}$ de ouro e foram realizadas elétron-micrografias em microscópio eletrônico de varredura (Modelo Jeol JSM 54 10), operando em $15 \mathrm{KV}$. Os dados foram submetidos à análise de variância por meio do programa SAS ${ }^{\circledR}$ (2001) e, em caso de significância, as médias foram comparadas pelo teste de Tukey a $5 \%$ de probabilidade.

$\mathrm{Na}$ rotina histológica, as amostras do intestino delgado foram fixadas por imersão em solução de Bouin durante 24 horas. Em seguida, foi realizada a lavagem das mesmas em álcool etílico a $70 \%$ e a desidratação em séries crescentes de álcool. As amostras foram recortadas, diafanizadas em benzol e processadas para inclusão em paraplast. A seguir, foram realizados seis cortes histológicos de sete micrômetros de espessura e corados segundo a técnica de Hematoxilina e Eosina (Tolosa et al. 2003) para cada animal. Posteriormente o material foi acondicionado em caixas histológicas numeradas de acordo com os tratamentos. As lâminas devidamente coradas foram analisadas ao microscópio óptico. Das amostras colhidas aos 14, 21 e 45 dias de idade, foram preparadas 384 lâminas histológicas contendo três cortes do intestino delgado que foram observadas em um fotomicroscópio binocular, realizando-se a seleção aleatória de 120 campos por tratamento. As 360 imagens pertinentes à avaliação morfométrica foram capturadas com o auxílio da microcâmera Olympus DP 11 acoplada ao microscópio e armazenadas em cartão de memória Smartmedia ${ }^{\circledR}$. As imagens, de interesse, do intestino delgado das aves foram descarregadas em um microcomputador e analisadas à morfometria com o auxílio do software Image Pro Plus ${ }^{\circledR}$. As características morfométricas do intestino delgado avaliadas incluíram o número, a altura e a largura das vilosidades intestinais e o número de células caliciformes do duodeno, jejuno e íleo. A nomenclatura anatômica utilizada foi a de Baumel et al. (1993).

\section{RESULTADOS}

No Quadro 1 observam-se que as médias de consumo de água da primeira à sétima semana de vida não apresentaram diferenças significativas entre os tratamentos $(p>0,05)$. Já o número mais provável de coliformes totais e de $E$. coli variou entre os tratamentos analisados (Quadros 2 e 3). A água não filtrada apresentou valores absolutos maiores em comparação à água filtrada, o que demonstra relevante contaminação de origem fecal nos galões que eram abastecidos pela água não filtrada (Quadro 3).

Quanto à morfologia intestinal, observou-se que a água filtrada favoreceu a manutenção da superfície intestinal do duodeno, jejuno e íleo, enquanto a água não filtrada deixou as vilosidades intestinais do jejuno e íleo com os ápices irregulares (Fig.4). Na Fig.5 observa-se a extrusão do ápice
Quadro 1. Valores médios \pm desvio padrão do consumo semanal de água filtrada e não filtrada por animal, no período de um a 49 dias de idade das aves

\begin{tabular}{ccc}
\hline Idade (dias) & Água filtrada $(\mathrm{mL})$ & Água não filtrada $(\mathrm{mL})$ \\
\hline $1-7$ & $36,5 \pm 0,26$ & $37,8 \pm 0,22$ \\
$8-14$ & $77,20 \pm 0,13$ & $75,00 \pm 0,13$ \\
$15-21$ & $135,60 \pm 0,21$ & $128,12 \pm 0,21$ \\
$22-28$ & $215,00 \pm 0,26$ & $214,06 \pm 0,34$ \\
$29-35$ & $285,62 \pm 0,48$ & $282,81 \pm 0,26$ \\
$36-42$ & $322,18 \pm 0,47$ & $320,31 \pm 0,62$ \\
$43-49$ & $323,12 \pm 0,57$ & $323,75 \pm 0,62$
\end{tabular}

Quadro 2. Valores médios \pm desvio padrão do log do número mais provável (NMP) de coliformes totais das amostras de água obtidas de bebedouros de água filtrada e de água e não filtrada no período de um a 45 dias de idade

\begin{tabular}{ccc}
\hline Idade & \multicolumn{2}{c}{ Coliforme total (NMP) } \\
\cline { 2 - 3 } & Água filtrada & Água não filtrada \\
\hline 1 & $0,76 \pm 1,18 \mathrm{~b}$ & $3,01 \pm 0,63 \mathrm{a}$ \\
11 & $1,12 \pm 1,13 \mathrm{~b}$ & $4,21 \pm 0,52 \mathrm{a}$ \\
18 & $3,02 \pm 1,81 \mathrm{a}$ & $3,53 \pm 1,36 \mathrm{a}$ \\
25 & $3,03 \pm 1,17 \mathrm{a}$ & $3,70 \pm 1,47 \mathrm{a}$ \\
32 & $1,02 \pm 1,23 \mathrm{~b}$ & $3,29 \pm 1,24 \mathrm{a}$ \\
39 & $3,35 \pm 0,70 \mathrm{a}$ & $3,67 \pm 0,82 \mathrm{a}$ \\
45 & $2,52 \pm 0,99 \mathrm{a}$ & $3,62 \pm 0,67 \mathrm{a}$ \\
Média & 2,18 & 3,57
\end{tabular}

Médias com letras diferentes na mesma linha diferem estatisticamente entre si.

Quadro 3. Valores médios \pm desvio padrão do log do número mais provável (NMP) de Escherichia coli das amostras de água obtidas de bebedouros de água filtrada e de água e não filtrada no período de quatro a 44 dias de idade

\begin{tabular}{ccc}
\hline Idade & \multicolumn{2}{c}{ Escherichia coli } \\
\cline { 2 - 3 } & Água filtrada & Água não filtrada \\
\hline 4 & $0,43 \pm 0,91 \mathrm{~b}$ & $2,48 \pm 0,32 \mathrm{a}$ \\
11 & $0,60 \pm 0,97 \mathrm{~b}$ & $3,37 \pm 0,50 \mathrm{a}$ \\
18 & $2,55 \pm 1,57 \mathrm{a}$ & $3,35 \pm 1,13 \mathrm{a}$ \\
25 & $1,94 \pm 1,79 \mathrm{a}$ & $2,98 \pm 1,69 \mathrm{a}$ \\
32 & $0,85 \pm 1,10 \mathrm{a}$ & $1,14 \pm 1,58 \mathrm{a}$ \\
39 & $2,01 \pm 1,51 \mathrm{a}$ & $1,54 \pm 1,34 \mathrm{a}$ \\
45 & $1,17 \pm 1,25 \mathrm{a}$ & $2,53 \pm 1,13 \mathrm{a}$ \\
Média & 1,36 & 2,48
\end{tabular}

Médias com letras diferentes na mesma linha diferem estatisticamente entre si.

da vilosidade do jejuno em frangos de corte que ingeriram água não filtrada, aos 45 dias de idade. Aves tratadas com água filtrada apresentaram menor densidade de vilos duodenais em relação a frangos de corte tratados com água não filtrada. Não houve aumento na densidade dos vilos da primeira à sexta semana $(p>0,05)$, evidenciando que aos sete dias de idade as aves já apresentavam número definido de vilosidades por área do intestino nas diferentes porções do intestino delgado (Quadro 4).

$\mathrm{Na}$ análise morfométrica, observou-se que a altura das vilosidades intestinais (Quadros 5, 9 e 13) e o número de células caliciformes (Quadros 8, 12 e 16) não diferiram $(p>0,05)$ entre os tratamentos empregados no período de um a 45 dias de idade Não houve diferença $(p>0,05)$ na largura das vilosidades duodenais de aves abatidas aos $14 \mathrm{e}$ 

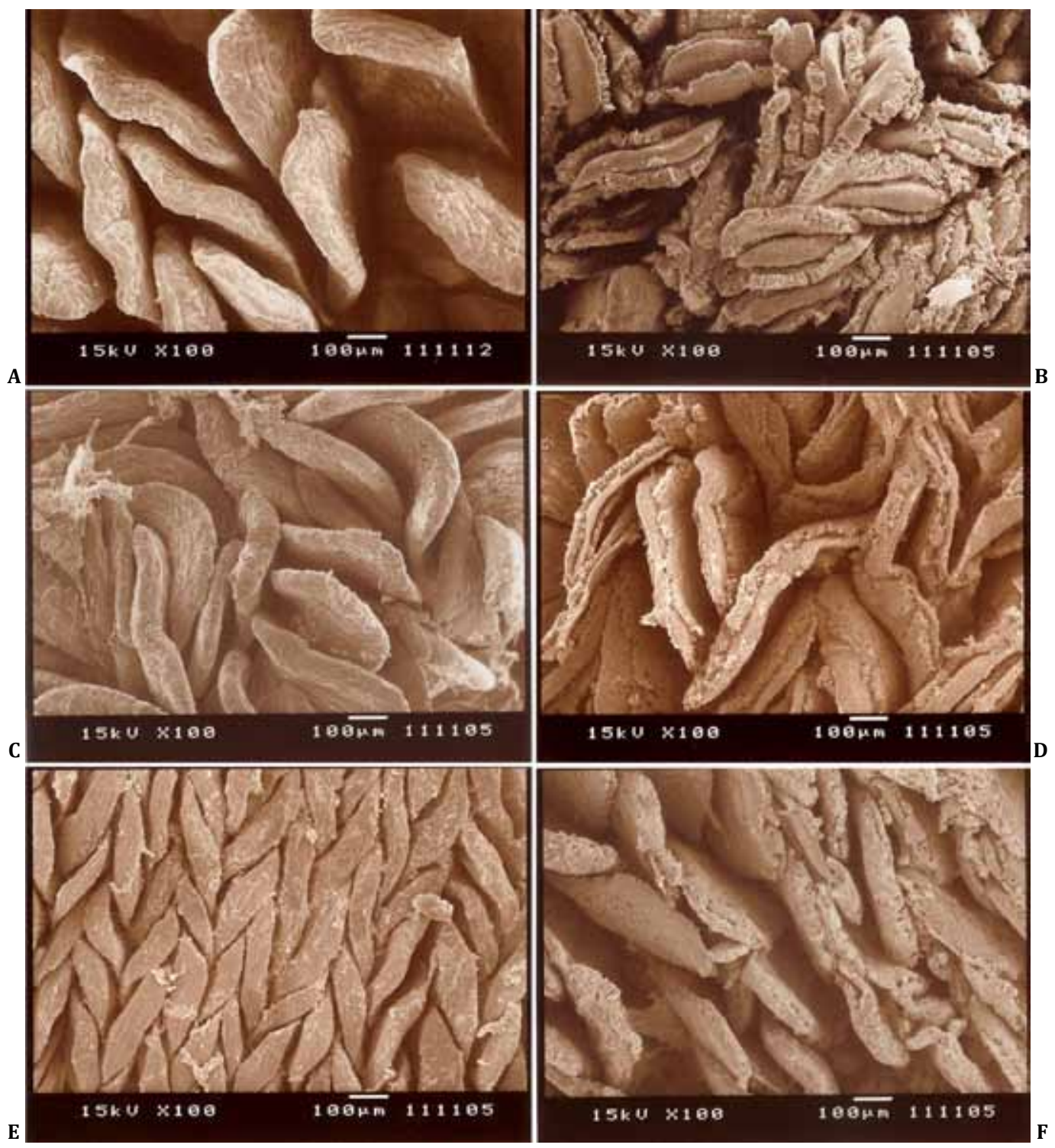

Fig.4. (A,B) Eletromicrografias do duodeno, (C,D) jejuno e (E,F) íleo de frangos de corte tratados $(\mathbf{A}, \mathbf{C}, \mathbf{E})$ com água filtrada e (B,D,F) com água não filtrada aos 45 dias de idade. $750 x$.

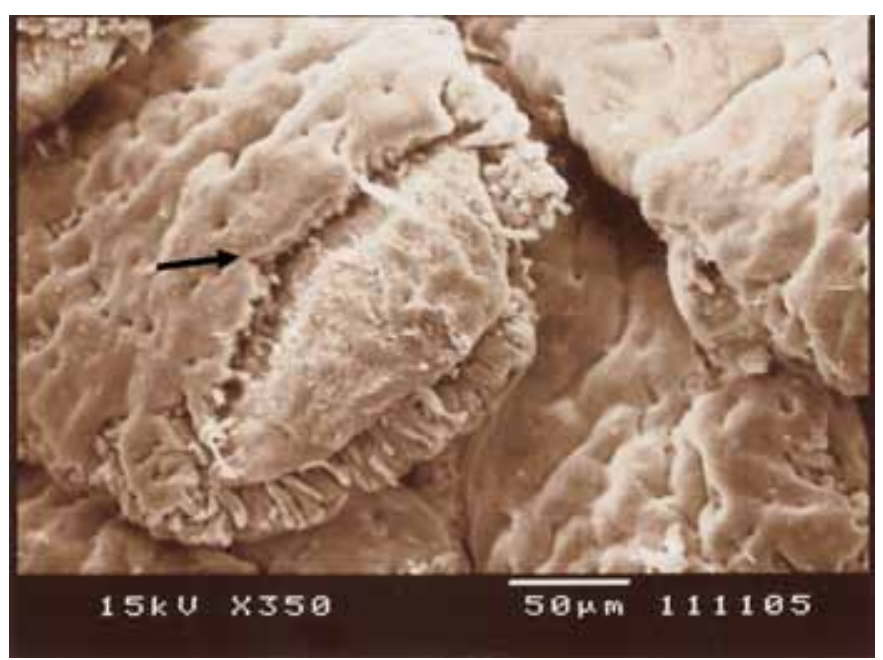

Fig.5. Eletromicrografia do jejuno de frangos de corte tratados com água não filtrada aos 45 dias de idade evidenciando extrusão em ápice da vilosidade (seta). 750x.
Quadro 4. Valores médios \pm desvio padrão da densidade de vilos (número de vilo/1.145.306 $\mu^{2}$ ) por segmento de intestino em frangos de corte tratados com água filtrada $e$ não filtrada de uma a seis semanas de idade

\begin{tabular}{lccc}
\hline Parâmetro avaliado & \multicolumn{3}{c}{ Densidade de vilos } \\
\cline { 2 - 4 } Tratamento & Duodeno & Jejuno & Íleo \\
\hline Água filtrada & $24,23 \pm 5,46 \mathrm{~b}$ & $30,52 \pm 7,45 \mathrm{a}$ & $37,07 \pm 6,28^{\mathrm{a}}$ \\
Água não filtrada & $27,93 \pm 8,07 \mathrm{a}$ & $32,53 \pm 9,64 \mathrm{a}$ & $37,02 \pm 7,99^{\mathrm{a}}$
\end{tabular}

Médias com letras iguais minúsculas na linha não diferem entre si.

21 dias de idade, enquanto na idade de 45 dias, a largura foi maior no tratamento com água não filtrada em relação à filtrada $(\mathrm{p}<0,05)(\mathrm{Quadro} 6)$. 0 tipo de água ingerido pelas aves não promoveu diferença $(\mathrm{p}>0,05)$ na largura das vilosidades intestinais dos segmentos subseqüentes, o jejuno e o íleo (Quadros 10 e 14). A profundidade de cripta diferiu entre os tratamentos $(p<0,05)$, com maiores médias no duodeno e no jejuno de frangos tratados com água não filtrada (Quadros 7, 11 e 15). 
Quadro 5. Valores médios \pm desvio padrão da altura das vilosidades intestinais do duodeno de frangos de corte de 14 a 45 dias de idade tratados com água filtrada e não filtrada

\begin{tabular}{ccc}
\hline Duodeno & \multicolumn{2}{c}{ Altura das vilosidades intestinais } \\
\cline { 2 - 3 } Idade (dias) & Água filtrada & Água não filtrada \\
\hline 14 & $1170,34 \pm 95,18$ & $1178,21 \pm 101,36$ \\
21 & $1149,34 \pm 153,66$ & $1197,10 \pm 137,32$ \\
45 & $1329,42 \pm 211,30$ & $1341,29 \pm 192,67$
\end{tabular}

Quadro 6. Valores médios \pm desvio padrão da largura das vilosidades intestinais do duodeno de frangos de corte de 14 a 45 dias de idade tratados com água filtrada e não filtrada

\begin{tabular}{|c|c|c|}
\hline \multirow{2}{*}{$\begin{array}{c}\text { Duodeno } \\
\text { Idade (dias) }\end{array}$} & \multicolumn{2}{|c|}{ Largura das vilosidades intestinais } \\
\hline & Água filtrada & Água não filtrada \\
\hline 14 & $100,61 \pm 12,33 a$ & $102,31 \pm 9,29 \underline{a}$ \\
\hline 21 & $113,15 \pm 9,78 a$ & $112,51 \pm 11,73^{\underline{a}}$ \\
\hline 45 & $115,61 \pm 11,61 b$ & $123,81 \pm 12,45 a$ \\
\hline
\end{tabular}

Médias com letras iguais minúsculas na linha não diferem entre si.

Quadro 7. Valores médios \pm desvio padrão da profundidade das criptas intestinais do duodeno de frangos de corte de 14 a 45 dias de idade tratados com água filtrada e não filtrada

\begin{tabular}{ccc}
\hline \multirow{2}{*}{$\begin{array}{c}\text { Duodeno } \\
\text { Idade (dias) }\end{array}$} & \multicolumn{2}{c}{ Profundidade das criptas intestinais } \\
\cline { 2 - 3 } & Água filtrada & Água não filtrada \\
\hline 14 & $198,75 \pm 21,30 \mathrm{a}$ & $200,62 \pm 15,65 \mathrm{a}$ \\
21 & $211,32 \pm 9,78 \mathrm{~b}$ & $250,72 \pm 20,11 \mathrm{a}$ \\
45 & $223,41 \pm 22,86 \mathrm{~b}$ & $265,14 \pm 33,82 \mathrm{a}$
\end{tabular}

Médias com letras iguais minúsculas na linha não diferem entre si.

Quadro 8. Valores médios \pm desvio padrão do número de células caliciformes do duodeno de frangos de corte de 14 a 45 dias de idade tratados com água filtrada e não filtrada

\begin{tabular}{ccc}
\hline \multirow{2}{*}{$\begin{array}{c}\text { Duodeno } \\
\text { Idade (dias) }\end{array}$} & \multicolumn{2}{c}{ Número de células caliciformes } \\
\cline { 2 - 3 } & Água filtrada & Água não filtrada \\
\hline 14 & $546 \pm 11,21$ & $531 \pm 32,18$ \\
21 & $567 \pm 49,30$ & $561,87 \pm 23,12$ \\
45 & $579 \pm 36,87$ & $571,20 \pm 47,61$
\end{tabular}

Quadro 9. Valores médios \pm desvio padrão da altura das vilosidades intestinais do jejuno de frangos de corte de 14 a 45 dias de idade tratados com água filtrada e não filtrada

\begin{tabular}{ccc}
\hline \multirow{2}{*}{$\begin{array}{c}\text { Jejuno } \\
\text { Idade (dias) }\end{array}$} & \multicolumn{2}{c}{ Altura das vilosidades intestinais } \\
\cline { 2 - 3 } & Água filtrada & Água não filtrada \\
\hline 14 & $1073,57 \pm 164,95$ & $1067,46 \pm 137,24$ \\
21 & $1085,12 \pm 159,24$ & $1072,42 \pm 134,28$ \\
45 & $1519,86 \pm 74,36$ & $1587,53 \pm 175,54$
\end{tabular}

\section{DISCUSSÃO}

Os valores médios do consumo de água para cada unidade experimental (boxe com 35 aves) se encontram no Quadro 1. A qualidade microbiológica da água não interferiu no consumo de água, resultado que difere de Gama \& Togashi (2007), que observaram que o consumo de água foi maior em poedeiras comerciais que receberam água filtrada em relação a não filtrada durante três ciclos de produção, graças ao ajuste do organismo animal à água de melhor qualidade. 0 sistema de bebedouros do tipo nipple reduziu o número de micro-organismos de origem fecal, mas não evitou contaminação da água filtrada e não filtrada obtida direta- mente dos bicos dos bebedouros pelas aves. A água não filtrada apresentou maior contaminação de origem fecal que a água filtrada. Semelhantemente, Pinto et al. (2010) observaram contaminação microbiológica da água de dessedentação animal por enterococos e micro-organismos mesófilos devido à introdução de material fecal no bebedouro

Quadro 10. Valores médios \pm desvio padrão da largura das vilosidades intestinais do jejuno de frangos de corte de 14 a 45 dias de idade tratados com água filtrada e não filtrada

\begin{tabular}{ccc}
\hline \multirow{2}{*}{$\begin{array}{c}\text { Jejuno } \\
\text { Idade (dias) }\end{array}$} & \multicolumn{2}{c}{ Largura das vilosidades intestinais } \\
\cline { 2 - 3 } & Água filtrada & Água não filtrada \\
\hline 14 & $97,33 \pm 9,87$ & $92,77 \pm 13,32$ \\
21 & $104,18 \pm 6,39$ & $101,47 \pm 8,71$ \\
45 & $114,25 \pm 12,83$ & $103,80 \pm 10,85$
\end{tabular}

Quadro 11. Valores médios \pm desvio padrão da profundidade das criptas intestinais do jejuno de frangos de corte de 14 a 45 dias de idade tratados com água filtrada e não filtrada

\begin{tabular}{ccc}
\hline Idade (dias) & Água filtrada & Água não filtrada \\
\hline 14 & $189,82 \pm 15,09$ & $199,44 \pm 26,50$ \\
21 & $230,96 \pm 12,65$ & $233,11 \pm 19,98$ \\
45 & $266,07 \pm 30,12$ & $269,38 \pm 37,01$
\end{tabular}

Quadro 12. Valores médios \pm desvio padrão do número de células caliciformes do jejuno de frangos de corte de 14 a 45 dias de idade tratados com água filtrada e não filtrada

\begin{tabular}{ccc}
\hline \multirow{2}{*}{$\begin{array}{c}\text { Jejuno } \\
\text { Idade (dias) }\end{array}$} & \multicolumn{2}{c}{ Número de células caliciformes } \\
\cline { 2 - 3 } & Água filtrada & Água não filtrada \\
\hline 14 & $570,08 \pm 15,18$ & $565,91 \pm 13,34$ \\
21 & $549,43 \pm 38,01$ & $556,87 \pm 20,12$ \\
45 & $574,43 \pm 32,87$ & $568,08 \pm 25,46$
\end{tabular}

Quadro 13. Valores médios \pm desvio padrão da altura das vilosidades intestinais do íleo de frangos de corte de 14 a 45 dias de idade tratados com água filtrada e não filtrada

\begin{tabular}{ccc}
\hline Íleo & \multicolumn{2}{c}{ Altura das vilosidades intestinais } \\
\cline { 2 - 3 } Idade (dias) & Água filtrada & Água não filtrada \\
\hline 14 & $732,30 \pm 123,62$ & $687,33 \pm 87,95$ \\
21 & $929,67 \pm 98,67$ & $919,40 \pm 101,34$ \\
45 & $956,59 \pm 100,18$ & $949,96 \pm 97,45$
\end{tabular}

Quadro 14. Valores médios \pm desvio padrão da largura das vilosidades intestinais do íleo de frangos de corte de 14 a 45 dias de idade tratados com água filtrada e não filtrada

\begin{tabular}{ccc}
\hline Íleo & \multicolumn{2}{c}{ Largura das vilosidades intestinais } \\
\cline { 2 - 3 } Idade (dias) & Água filtrada & Água não filtrada \\
\hline 14 & $100,61 \pm 12,33$ & $102,31 \pm 9,29$ \\
21 & $113,15 \pm 9,78$ & $112,51 \pm 11,73$ \\
45 & $115,61 \pm 11,61$ & $123,81 \pm 12,45$
\end{tabular}

Quadro 15. Valores médios \pm desvio padrão da profundidade das criptas intestinais do íleo de frangos de corte de 14 a 45 dias de idade tratados com água filtrada e não filtrada

\begin{tabular}{ccc}
\hline Íleo & \multicolumn{2}{c}{ Profundidade das criptas intestinais } \\
\cline { 2 - 3 } Idade (dias) & Água filtrada & Água não filtrada \\
\hline 14 & $228,60 \pm 38,382$ & $220,77 \pm 29,41$ \\
21 & $297,31 \pm 32,87$ & $245,07 \pm 52,02$ \\
45 & $233,72 \pm 60,25$ & $247,90 \pm 36,15$
\end{tabular}


Quadro 16. Valores médios \pm desvio padrão do número de células caliciformes do íleo de frangos de corte de 14 a 45 dias de idade tratados com água filtrada e não filtrada

\begin{tabular}{ccc}
\hline \multirow{2}{*}{$\begin{array}{c}\text { Íleo } \\
\text { Idade (dias) }\end{array}$} & \multicolumn{2}{c}{ Número de células caliciformes } \\
\cline { 2 - 3 } 14 & $580,60 \pm 146,49 \mathrm{~b}$ & $714 \pm 126,76 \mathrm{a}$ \\
21 & $664,31 \pm 137,26 \mathrm{a}$ & $703,19 \pm 122,48 \mathrm{a}$ \\
45 & $705,61 \pm 138,59 \mathrm{a}$ & $720,20 \pm 130,61 \mathrm{a}$
\end{tabular}

Médias com letras iguais minúsculas na linha não diferem entre si.

toda vez que os animais ingeriam água. Cepas de Escherichia coli persistem várias horas na água de dessedentação devido à sua sobrevivência em biofilmes (Bukh et al. 2012). A intensificação produtiva no setor avícola e a alta densidade de animais propiciam condições favoráveis à ocorrência e à disseminação de alguns patógenos, como a Escherichia coli, que pode provocar infecções graves nos animais e no homem (Silva et al. 2012). Outro agravante relacionado com o ambiente e a ave é que a via oral é a principal porta de entrada de micro-organismos fecais, tendo como consequência colonização intestinal persistente (Andreatti Filho et al. 1993). Além disso, as aves que ingerem bactérias de origem entérica apresentam maior probabilidade de eliminarem Salmonella spp., contaminando o ambiente e servindo como fonte deste micro-organismo para aves saudáveis (Alchalaby et al. 1985). No presente trabalho, infere-se que as aves que tiveram acesso à água não filtrada ficaram expostas ao maior número de micro-organismos de origem fecal, e, portanto, eram susceptíveis à ocorrência de distúrbios gastrintestinais. Ainda que os valores de NMP estivessem abaixo do que é permitido pela Resolução n. 396/08 do Conselho Nacional do Meio Ambiente - CONAMA (Brasil 2008), sugere-se a criação de uma nova resolução que proponha os mesmos parâmetros de potabilidade propostos para a água de consumo humano. Neste contexto, a utilização de um filtro no galpão avícola pode atuar como medida profilática na prevenção de enfermidades gastrintestinais, pois, de acordo com Duarte et al. (2014), a água destinada ao consumo animal deve atender ao mínimo de exigências de padrões de qualidade para garantir consumo adequado, sem provocar injúrias aos animais devido à má qualidade, como contaminação microbiológica ou química. Recomenda-se a implantação de um programa profilático regular das linhas de água, impedindo a formação de biofilmes e a protegendo as aves contra contaminação química e infecção bacteriana através da água de bebida (Soares et al. 2012). A Instrução Normativa 36/12 do Ministério da Agricultura, Pecuária e Abastecimento exige o comprobatório da qualidade microbiológica da água de consumo das aves, conforme os padrões definidos pela legislação vigente (Brasil, 2012).

Ao analisar a influência da qualidade microbiológica da água sobre a morfologia do intestino, observou-se que duodeno de frangos de corte tratados com água filtrada apresentou menor densidade de vilos que o de animais tratados com água não filtrada, provavelmente como resposta fisiológica à qualidade de água (Quadro 3). Este resultado difere de autores que utilizaram aditivos, como a glutamina, que aumentou a densidade de vilos (Silva et al. 2007). Já
Pelicano et al. (2005) observaram que aditivos nutricionais aumentaram a densidade dos vilos ileais, sem interferir no duodeno e no jejuno. Os arranjos das vilosidades intestinais são controlados pela absorção dos nutrientes (Aptekmann et al. 2001). As aves que ingeriram água não filtrada apresentaram maior densidade de vilos no duodeno que as que consumiram água filtrada (Quadro 3), o que demonstra que a quantidade de micro-organismos presentes na água pode interferir diretamente na estrutura do epitélio do trato intestinal. Este resultado tem grande relevância, considerando-se que a absorção de água e minerais ocorre ao longo de todo intestino delgado, principalmente no duodeno e jejuno. Maior densidade de vilos representa a necessidade estrutural de ampliar a superfície absortiva do intestino delgado em relação a um determinado elemento presente no lúmen intestinal (Maiorka et al. 2002).

Quando existe algum estímulo ou agente, o intestino responde com aceleração ou atenuação do turnover celular (Leser \& Molbak 2009). Qualitativamente, a extrusão dos vilos foi observada em animais que receberam água não filtrada (Fig.4). 0 aumento na taxa de extrusão está associado com a proliferação celular na base dos vilos e consequente aumento da profundidade das criptas intestinais, como mecanismo compensatório para recuperar a perda epitelial do ápice das vilosidades (Furlan et al. 2004).

No que diz respeito à morfometria, a qualidade de água não interferiu na quantidade de células caliciformes do intestino delgado de frangos que ingeriram água filtrada e não filtrada ( $p>0,05)$. Lea et al. (2013) adicionaram carboidratos provenientes da parede celular de Saccharomyces cerevisiae à dieta e também não observaram efeito significativo sobre o número de células caliciformes no duodeno. Estes resultados diferem do que já foi relatado por outros autores, em que fatores danosos à mucosa, como o jejum (Nakage 2007) e a presença de micro-organismos patogênicos (Pickler et al. 2012, 2014), elevam o número de células caliciformes. Já Bona et al. (2012) utilizaram composto vegetal à base de óleo essencial de orégano, alecrim, canela e extrato de pimenta vermelha na dieta de aves desafiadas com Salmonella Enteritidis e observaram aumento do número de células caliciformes no duodeno do grupo tratado, sugerindo maior quantidade de muco para controle de bactérias patogênicas intestinais.

Os valores médios da altura das vilosidades intestinais não diferiram no duodeno no período de um a 45 dias de idade em ambos os tratamentos. Resultado semelhante também foi observado por Giannenas et al. (2010) após adição do cogumelo Agaricus bisporus à dieta que não promoveu efeitos tróficos na mucosa intestinal de frangos de corte, embora tenha favorecido a microbiota intestinal. Já Lei et al. (2015) observaram aumento na altura das vilosidades intestinais a partir dos 21 dias de idade ao adicionarem Bacillus amyloliquefaciens à dieta como alternativa ao uso de melhoradores do crescimento na prevenção de enfermidades.

A largura das vilosidades do duodeno variou aos 45 dias de idade, sendo maior nas aves tratadas com água não filtrada em relação à filtrada $(\mathrm{p}<0,05)$ (Quadro 6). Estes dados evidenciam que as aves tratadas com água não filtrada 
apresentaram as vilosidades intestinais com sua superfície ampliada, provavelmente para melhorar a capacidade absortiva da primeira porção do intestino delgado, considerando que o duodeno é a região do intestino delgado em que a absorção de elementos digeridos da dieta é mais significativa em relação aos outros segmentos (Maiorka et al. 2002).

A maior profundidade de cripta no duodeno e jejuno de frangos tratados com água não filtrada evidencia a necessidade de renovação celular das vilosidades intestinais em resposta à qualidade de água de dessedentação. 0 que difere de Murakami et al. (2012), que observaram que suplementação com elementos que favorecem a morfologia intestinal, como a arginina, reduzem a profundidade da cripta já na primeira semana de vida.

\section{CONCLUSÕES}

Os resultados do presente trabalho demonstram que a instalação de um filtro de água acoplado ao sistema de bebedouros tipo nipple permitiu o fornecimento de água de dessedentação de melhor qualidade microbiológica graças à redução da quantidade de coliformes totais e de Escherichia coli, e, possibilitou a manutenção da integridade intestinal de frangos de corte que ingeriram água filtrada no período de um a 45 dias de idade.

A água potável, recomendada ao consumo humano, deve ser oferecida às aves e monitorada periodicamente, para garantir a prevenção de enfermidades gastrintestinais.

Agradecimentos.- À Dra. Nilce Maria Soares e aos docentes, Prof. Dr. Otto Mack Junqueira e Prof. Dr. Luis Augusto do Amaral e pela disponibilidade e atenção durante as etapas de desenvolvimento do trabalho. À Fapesp Fundação de Amparo à Pesquisa do Estado de São Paulo, pelo incentivo e apoio financeiro para que esta pesquisa fosse realizada. À empresa Hidrofiltros $^{\circledR}$, pela doação do filtro utilizado durante o experimento.

\section{REFERÊNCIAS}

Alchalaby Z.A.M., Hinton A.H. \& Linton A.H. 1985. Failure of drinking water sanitization to reduce the incidence of natural Salmonella in broiler chicken. Vet. Rec. 116(4):364-365.

Andreatti Filho R.L., Silva E.M. \& Balen L. 1993. Efeito da via de inoculação na patogenicidade de amostras patogênicas e apatogênicas de Escherichia coli em galinhas. Revta Saúde Públ. 45(5):475-486.

Aptekmann K.P., Baraldi-Artoni S.M., Stefanini M.A. \& Orsi M.A. 2001. Morphometric analysis of the intestine of domestic quails (Coturnix coturnix japonica) treated with different levels of dietary calcium. Anat. Histol. Embryol. 30(5):277-280.

Ashida H., Ogawa M., Kim M., Mimuro H. \& Sasakawa C. 2012. Bacteria and host interactions in the gut epithelial barrier. Nat. Chem. Biol. 8(1):36-45.

Baumel J.J., King A.S., Breazille J.E., Evans H.E. \& Vanden Berge J.C. 1993. Handbook of avian anatomy: nomina anatomica avium. $2^{\text {nd }} e d$. Nutall Ornithological Club, Cambridge, p.24-338.

Brasil 2008. Resolução CONAMA no 396, de 3 de abril de 2008. Dispõe sobre a classificação e diretrizes ambientais para o enquadramento das águas subterrâneas e dá outras providências. Diário Oficial da República Federativa do Brasil, Poder Executivo, Brasília, DF, 3 abr. 2008, Seção Resoluções, p.71.

Brasil 2012. Instrução Normativa no 36, de 6 de dezembro de 2012. Ministério da Agricultura e Abastecimento. Aprova o Manual de Procedimentos Operacionais da Vigilância Agropecuária Internacional. Diário Oficial da República Federativa do Brasil, Poder Executivo, Brasília, DF,
$6 \mathrm{dez}, 2012$, p.60.

Bona T.D.M.M., Pickler L., Miglino L.B., Kuritza L.N., Vasconcelos S.P. \& Santin E. 2012. Óleo essencial de orégano, alecrim, canela e extrato de pimenta no controle de Salmonella, Eimeria e Clostridium em frangos de corte. Pesq. Vet. Bras. 32(5):411-418.

Bukh A.S., Hansen N.E. \& Roslev P. 2012. Detection and persistence of clinical Escherichia coli in drinking water evaluated by a rapid enzyme assay and qPCR . Adv. Microbiol. 2(3):252-262.

Collet S.R. 2012. Nutrition and wet litter problems in poultry. Anim. Feed Sci. Technol. 173:65-75.

Corless A.B. \& Sell J.L. 1999. The effects of delayed access to feed and water on the physical and functional development of the digestive system of young turkeys. Poult. Sci. 78(8):1158-1169.

Duarte K.M.R., Gomes L.H., Dozzo A.D.P., Rocha F., Lira S.P. \& Demarchi J.J.A.A. 2014. Qualidade microbiológica da água para consumo animal. Bolm Indústr. Anim. 71(2):35-142.

Fairchild B.D. \& Ritz C.W. 2009. Poultry Drinking Water Primer. Extension Poultry Scientists, University of Georgia, p.1-6.

Furlan L.R., Macari M. \& Luquetti B.C. 2004. Como avaliar os efeitos do uso de prebióticos, probióticos e flora de exclusão competitiva. Anais Simpósio Técnico de Incubação, Matrizes de Corte e Nutrição, Balneário Camboriú, SC, p.6-28. (Resumo)

Gama N.M.S.Q. \& Togashi C.K. 2007. Relato do desempenho de Poedeiras Comerciais consumindo água filtrada. Artigo em Hypertexto. Disponível em <http://www.biologico.sp.gov.br/artigos_ok.php?id_artigo=50> Acesso em agosto de 2012.

Gama N.M.S.Q., Togashi C.K., Ferreira N.T., Buim M.R., Guastalli E.L. \& Fiagá D.A.M. 2008. Conhecendo a água utilizada para as aves de produção. Biológico, São Paulo, 70(1):43-49.

Giannenas I., Tontis D., Tsalie E., Chronis E.F., Doukas D. \& Kyriazakis I. 2010. Influence of dietary mushroom Agaricus bisporus on intestinal morphology and microflora composition in broiler chickens. Res. Vet. Sci. 8:78-84

Giannenas I., Papadopoulos E., Tsalie E., Triantafillou El., Henikle S., Teichmann K. \& Tontis D. 2012. Assessment of dietary supplementation with probiotics on performance, intestinal morphology and microflora of chickens infected with Eimeria tenella. Vet. Parasitol. 188(1/2):31-40.

Gomide-Junior M.L., Sterzo E.V., Macari M. \& Boleli I.C. 2004. Use of scanning electron microscopy for the evaluation of intestinal epithelium integrity. Revta. Bras. Zootec. 33(6):1500-1505.

Gruber J.S., Ercumen A. \& Colford J.M. 2014. Coliform bacteria as indicators of diarrheal risk in household drinking water: systematic review and meta analysis. Plos One. 9(9):1-14.

Lea H., Spring P., Taylor-Pickard J. \& Burton E. 2013. A natural carbohydrate fraction Actigen ${ }^{\mathrm{TM}}$ from Saccharomyces cerevisiae cell wall: effects on goblet cells, gut morphology and performance of broiler chickens. J. Appl. Anim. Nutr. 1(9):1-17.

Lei X., Piao X., Ru Y., Zhang H., Péron A. \& Zhang H. 2015. Effect of Bacillus amyloliquefaciens-based direct-fed microbial on performance, nutrient utilization, intestinal morphology and cecal microflora in broiler chickens. Asian Austral. J. Anim. Sci. 28(2):239-246.

Leser T.D. \& Mølbak L. 2009. Better living through microbial action: the benefits of the mammalian gastrointestinal microbiota on the host. Environ. Microbiol. 11(9):2194-2206.

Murakami A.E., Fernandes J.I.M., Hernandes L. \& Santos T.C.S. 2012. Effects of starter diet supplementation with arginine on broiler production performance and on small intestine morphometry. Pesq. Vet. Bras. 32(3):259-266.

Maiorka A., Boleli I.C. \& Macari M. 2002. Desenvolvimento e reparo da mucosa intestinal, p.113-123. In: Macari M., Furlan R.L. \& Gonzales E. (Eds), Fisiologia Aviária Aplicada aos Frangos de Corte. $2^{\underline{a}}$ ed. Facta, Campinas.

Maiorka A. 2002. Efeitos da idade da matriz, do jejum, da energia da ração e da glutamina, sobre o desenvolvimento da mucosa intestinal e atividade enzimática do pâncreas enzimática do pâncreas de pintos de corte. 
Tese de Doutorado em Produção Animal, Faculdade de Ciências Agrárias e Veterinárias, Universidade Estadual Paulista, Jaboticabal, SP. 103p.

Nakage E.S. 2007. Respostas fisiológicas de pintos submetidos a diferentes períodos de jejum: parâmetros hematológicos e intestinais. Tese de Doutorado em Produção Animal, Faculdade de Ciências Agrárias e Veterinárias, Universidade Estadual Paulista, Jaboticabal, SP. 86p.

Odonkor S.T. \& Ampofo J.K. 2013. Escherichia coli as an indicator of bacteriological quality of water: an overview. Microbiol. Res. 4(1):5-11.

Pelicano E.R.L. 2006. Desempenho, qualidade de carne e desenvolvimento da mucosa intestinal de frangos produzidos com probióticos e prebióticos. Tese de Doutorado em Produção Animal, Faculdade de Ciências Agrárias e Veterinárias, Universidade Estadual Paulista, Jaboticabal, SP. $117 \mathrm{p}$.

Pelicano E.R.L., Souza P.A., Figueiredo D.F., Boiago M.M., Carvalho S.R. \& Bordon V.F. 2005. Intestinal mucosa development in broiler chickens fed natural growth promoters. Braz. J. Poult. Sci. 7(4):221-229.

Pickler L., Hayashil R.M., Lourenço M.C., Miglino L.B., Caron L.F., Beirão B.C.B., Silva A.V.F. \& Santin E. 2012. Avaliação microbiológica, histológica e imunológica de frangos de corte desafiados com Salmonella Enteritidis e Minnesota e tratados com ácidos orgânicos. Pesq. Vet. Bras. 32(1):27-36.

Pickler L., Muniz E.C., Kuritza L.N., Lourenço M.C. \& Santin E. 2014. Resposta imunológica e uso de ácidos orgânicos em frangos desafiados com Salmonella Minnesota. Acta. Scient. Vet. 42(1):1-9.

Pinto F.R., Sampaio C.F., Malta A.S., Lopes L.G., Pereira G.T. \& Amaral L.A. 2010. Características da água de consumo animal na área rural da microbacia do Córrego Rico, Jaboticabal, SP. Ars Vet. 26:153-159.
Quinn P.J., Markey B.K., Carter M.E., Donnelly W.J. \& Leonard F.C. 2010. Veterinary Microbiology and Microbial Disease. $10^{\text {th }}$ ed. Blackwell Publishing, Oxford, p.457-460.

SAS 2001. Statistical Analysis System User's Guide: stat. version. $8^{\text {th }}$ ed. SAS Institute, Cary. 1464p.

Sen S., Ingale S.L., Kim Y.W., Kim J.S., Kim K., Lohakare J.D., Kim E.K., Kim H.S., Ryu M.H., Kwon I.K. \& Chae B.J. 2012. Effect of supplementation of Bacillus subtilis LS 1-2 to broiler diets on growth performance, nutrient retention, caecal microbiology and small intestinal morphology. Res. Vet. Sci. 93(1):264-268.

Silva A.V.F., Maiorka A., Borges S.A., Santin S., Boleli I.C. \& Macari M. 2007. Surface area of the tip of the enterocytes in small intestine mucosa of broilers submitted to early feed restriction and supplemented with glutamine. Int. J. Poult. Sci. 6(1):31-35.

Silva I.M.M., Baliza M., Santos M.P., Rebouças L.T., Rocha E.V.S., Santos V.A., Silva R.M. \& Evêncio-Neto J. 2012. Presença de Escherichia coli em fígados de frangos provenientes de matadouros avícolas. Revta. Bras. Saúde Prod. Anim. 13(3):694-700.

Shibata T., Solo-Gabriele H.M., Fleming L.E. \& Elmir S. 2004. Monitoring marine recreational water quality using multiple microbial indicators in a urban tropical environment. Water Res. 38(13):3119-3131.

Soares N.M., Amoroso L. \& Amoroso P. 2012. Qualidade de água de bebida para aves, p.289-307. In: Macari M. \& Soares N.M. (Eds), Água na Avicultura Industrial. $2^{\mathrm{a}}$ ed. Facta, Campinas.

Tolosa E.M.C., Rodrigues C.J., Behmer O. \& Freitas Neto A.G. 2003. Manual de Técnicas para Histologia Normal e Patológica. $2^{\underline{a}}$ ed. Manole, São Paulo, p.121-123. 